S sciendo

\title{
Image-based de re Thought
}

\author{
Xiaoqiang Han \\ Queen's University at Kingston
}

Disputatio Vol. 2, No. 24

May 2008

DOI: $10.2478 /$ disp-2008-0004

ISSN: 0873-626X 


\title{
Image-based de re thought
}

\author{
Xiaoqiang Han \\ Queen's University at Kingston
}

\begin{abstract}
In this paper I argue that in addition to the three generally recognized kinds of de re thought, i.e., perception-based, memory-based and communication-based thought, there is a kind of de re thought, which is based on image and cannot be assimilated to any of these recognized kinds of de re thought. I call it simply image-based de re thought. Although image-based thought shares some similarities with the other kinds of de re thought, it should and can be distinguished from each of them. The focus of this paper is on the distinction between image-based thought and perception-based thought, as it is this distinction that is either overlooked or denied by philosophers who have no difficulty seeing the distinct role of images in our thinking about things in the world.
\end{abstract}

It has been generally accepted as useful by philosophers that our thoughts about things be roughly divided into two kinds, de re and de dicto. ${ }^{1}$ According to one account of the distinction, to think of something in a de re way is to think of it directly, that is, as unmediated by some concept expressed by 'the F', whereas to think of something de dicto is to think of whatever fits a certain description. ${ }^{2}$ A paradigm case of de re thought is when we are perceiving the thing that we are thinking about. In addition, de re thought can also be thought about things that we have previously perceived and presently remember, and thought about things that we are informed of by others who previously perceived (or in some cases are presently perceiving) them. These are the three types of de re thought which are sometimes called (1) perception-based thought, (2) memory-based thought, and

\footnotetext{
${ }^{1}$ Discussions on the de re / de dicto distinction in recent history are believed to have started with Quine's 'Quantifiers and Propositional Attitudes', followed by a flurry of publications on the subject.

${ }^{2}$ While I am aware of the wide disparity in the literature as to what counts as a de re thought or a de dicto one, my discussion is based on Kent Bach's account in Thought and Reference (1987: 11-45), which I have found most persuasive.
}

Disputatio, Vol. II, No. 24, May 2008 
(3) communication-based thought respectively. ${ }^{3}$ While not all of them are recognized by all the philosophers who recognize the first ${ }^{4}$, they are thought to be exhaustive by those who recognize all of them $^{5}$. Like the second group of people, I recognize all three and consider the arguments for such recognition to be quite conclusive, given the basic understanding of the de re/de dicto distinction to which I subscribe. But unlike these people, I think that they are not the only ones that can be called de re. There is at least one additional type of thought, which is when we are perceiving an image of something that we are thinking about.

By 'an image' I mean a perceptual representation of the perceptual properties of something. A typical example would be a portrait of a person. Though the word 'image' is often used as also a shorthand for 'mental image', it is not so used here to avoid confusion. A different word 'imagery' will be used interchangeably with 'mental image'. An image is most often visual, but it can also be auditive or perhaps even tactile. ${ }^{6}$ The examples I choose, however, will be mainly visual im-

${ }^{3}$ Bach 1987: 11.

${ }^{4}$ Strawson, for instance, holds that we can think of something we do not perceive only either by description or in terms of its spatio-temporal relation to things we perceive (see Strawson 1959: 17ff). By this, Strawson effectively denies the possibility of memory-based and communication based de re thought. The difficulty in explicating how the paradigm case of de re thought can be truly extended to other cases such as that of memory is also recognized by Tylor Burge, who nevertheless thinks that the extension is in some way justified (see Burge 1977: 361-2).

${ }^{5}$ Burge (1977), Beebe (1979), Evans (1982), Bach (1987) and Kaplan (1989) all consider the only types of de re thought to be the three. Bach writes, 'When the audience has no independent de re way to think of the referent (call this the 'pure' case) [i.e., based on perception or memory], the speaker must use a name to succeed in expressing a de re attitude about it. The reason ... is that names make up the only kind of de re mode of presentation that a speaker can actually display to a hearer' (Bach 1987: 25). The possibility of the speaker displaying an image as a de re mode of presentation to a hearer is clearly excluded.

${ }^{6}$ A playback of a recorded thunder is an auditive image of the thunder taking place some time in the past, and a broadcast of a singing by Callas is an auditive image of Callas, though it can also be considered as an image of her singing depending on the context. But the tactile features of a sculpture, e.g., its shape, the smoothness of its surface, may only be regarded as constituting an image of the tactile features of a certain person (e.g., Rodin's Balzac), not an image of the person himself, when the sculpture is created to represent that particular individual, not of 
ages, because quite understandably visual images provide the clearest case for our analysis. I will ignore the difficulties presented by nonvisual images, which do not seem to me fundamental. An image can be of something either real or fictional. It can be either a product of imagination (e.g., a picture of a unicorn, or a picture of Notre-Dame de Paris by someone who never visited the French capital) or a result of a 'copying' process, in which some object is actually presented for the image to be made to resemble it, with or without direct human involvement (e.g., a photograph either shot by someone or done purely mechanically). ${ }^{7}$ Both real and fictional things can be imagined, but only real things can be 'copied'. I will limit my discussion only to those images that are resulted from 'copying', and it is the images with this characteristic that form the basis for the kind of thought that I refer to as image-based thought. ${ }^{8}$ My argument is that although image-based thought shares similarities of various degrees with de dicto thought and all three aforementioned types of de re thought, it constitutes a distinct kind that is de re in nature but cannot be assimilated into any de re thought that has been recognized. In the following I intend to show just how this is the case. Given that image-based thought can be relatively easily distinguished from de dicto thought and memory-based and communication-based de re thought, I will focus on the distinction between image-based thought and perception-based

a type of people (e.g., a Roman soldier) or an imaginary figure (e.g., Poseidon). This is due perhaps to the nature of touch. It should also be noted that a tactile image is not a visual mental image (imagery) created in the mind through touch.

${ }^{7}$ An ordinary, rough standard of resemblance will suffice for my purposes, and it need not presuppose any 'naïve' naturalist theory of pictorial representation.

${ }^{8}$ Therefore I will not consider such cases as the following, which may also be deemed as image representation. There are images that are created based solely on descriptions (e.g., a sketch of a suspect is done based on the descriptions provided by some witness, and not on the artist's perception of the suspect), such that they are akin to definite descriptions used purely 'attributively': An image of this kind may represent whatever fits it, though the uniqueness of the image, which is determined by the exactness and accuracy of the depiction, is often a purely practical matter, as a complete definite depiction is much less achievable than a complete definite description. There can also be indefinite images, which like indefinite descriptions, may depict things in a general, indefinite way. For example, an image may depict a man, but no man in particular. And an image can even depict things that do not exist (a golden mountain, Zeus), though it may not be able to depict logically impossible entities such as a round square. 
thought. It is precisely this distinction that is so often either overlooked or denied altogether, despite the fairly wide appreciation of the distinct role of images in our thinking about things in the world.

Suppose that someone comes across the portrait of Louis XIV by Hyacinthe Rigaud for the first time, with virtually no background information about this painting, even no knowledge of the title of the painting from which she may well infer the name of the person in the painting, due perhaps to her laziness that prevents her from taking a simple look at the description beside. Now the viewer of this painting, while looking at the painting, may form various thoughts about the figure in the painting - she is not just thinking about the painting per se, e.g., the rich and brilliant colors and the majestic and grandiloquent tone marvelously deployed to befit the slightly mannered figure, and so on; rather she is thinking of the person in the painting. She might be wondering, for instance, who this heavily dressed man is, how old he is, why he wears a pair of high-heeled shoes (or rather slippers) like a woman, and perhaps whether his huge wig is meant to hide his baldness.

It seems clear that by simply looking at the painting, the viewer does not need to employ any description such as 'the king of France who reigned between 1643 and 1715' in order to think of Louis XIV. ${ }^{9}$ She may say to herself as she would do in the presence of the king himself, 'he is probably bald' or 'this is probably a bald fellow'. Although like a concept, an image mediates between the viewer and the object being thought of, being an object of perception, it is clearly not a concept, something that can only be entertained in the mind, and not perceived by the senses. ${ }^{10}$ Insofar as the viewer, when thinking of an object through its image, is not mediated by a concept expressed by a description, she cannot be said to think of it descriptively. The differences between image-based thought and the other two forms of de re thought, namely, memory-based thought and communication-based thought, are also readily noticeable. Memorybased thought often, though not always, involves imageries, which are mental and private, and is necessarily about things the thinker per-

\footnotetext{
${ }^{9}$ Of course, the viewer may choose to think of the king descriptively, that is, as 'the man represented by this painting' or 'the person who looks thus-and-so'.

${ }^{10}$ Only a physical token of a word expressing a concept can be perceivable by the senses.
} 
ceived before, whereas image-based thought is based on images which are, by contrast, physical and publicly sharable, and can be of things which the thinker has never perceived and in some cases are never perceived by anyone. Image-based thought is distinguishable from communication-based thought for the reason that images must, but names (or tokens of names) need not, bear perceptual resemblance to the things they represent at a tolerable degree, although the former may just be as 'rigid' as the latter with regard to their relation to the things they represent. Now the question is whether we can with the same ease distinguish image-based thought from perception-based thought. The answer would seem in the positive, given the obvious difference between images of things and things themselves - no one would deny, for instance, the difference between the portrait of Louis XIV by Rigaud which is now displayed in the Louvre and the king himself who exists no more. But it is less obvious whether this difference guarantees the difference between image-based thought (thinking of something through its image) and perception-based thought (thinking of it by perceiving it).

It may be argued that although an image of something and the thing itself are vastly different, the perception of the image and the perception of the thing itself are not different in any significant way, which in turn may provide the grounds for denying any real difference between image based thought and perception based thought. Now the 'transparency thesis' presented by Kendall Walton in his celebrated paper 'Transparent Pictures: On the Nature of Photographic Realism' is precisely aimed at showing the absence of any theoretically relevant difference between perceiving an image (a photograph) and perceiving the thing it represents. ${ }^{11}$ According to Walton, when one sees a photograph of $\mathrm{X}$, he really sees $\mathrm{X}$ itself, just as one sees it through a window, a telescope or its reflection in a mirror. Such seeing, Walton warns, should not be taken as merely 'fictional'. If we say that we see Notre-Dame de Paris by looking at a photograph of it, we do not mean that we have the impression of seeing the cathedral, in the way we have the impression of seeing a

\footnotetext{
${ }^{11}$ Walton's main focus is photographs, which for him are fundamentally different from other kinds of images such as paintings. But his characterizations of them can nonetheless be generalized to apply to paintings and other representational media that are used for 'copying'. A separate argument for the generalization may be needed, but I will not pursue it in the present due to the scope of the paper.
} 
camel in the clouds. As Walton puts it, 'the viewer of a photograph sees, literally, the scene that was photographed' (Walton 1983: 252. Italics mine). Like eyeglasses, photographs are transparent. The viewer sees what is photographed through the photograph.

As Walton admits, the plausibility of his transparency thesis is derived largely from some slippery slope considerations. At the high end of the slope, we have the clearest case of seeing through. 'No one will deny that we see through eyeglasses, mirrors, and telescopes' (Walton 1983: 252). With this clearly established, we move on to allowing seeing something on live television broadcasts, then seeing it via delayed broadcasts, and finally we accept seeing something through photographs. ${ }^{12}$ While there are differences between these cases, Walton argues, none of them is significant enough to justify recognizing a basic theoretical distinction between seeing things and not doing so. What is essential to each case of seeing, then, is the characteristic of being in contact with, which determines each case as a case of seeing. One is in contact with things, when he 'either sees them with the naked eye or sees mirror images or photographs or fossils or footprints of them'. ${ }^{13}$ Such a contact may be understood as an unmediated relation between someone who is said to see and something that is said to be seen by her, unmediated by any concepts, beliefs or thoughts about that thing, and especially those of others. ${ }^{14}$

\footnotetext{
${ }^{12}$ However, seeing through photographs may not be the low end of the slippery slope. If we extend the slope and slide down further, Walton suggests, we can even say that we see ancient marine organisms and ancient animals' feet when looking at fossils and footprints (see Walton 1983: 275n).

${ }^{13}$ Walton writes, 'I repeat that my point needn't be made in terms of vision or perception. One might prefer to introduce a new notion, to speak of being 'in contact with' things, for instance, when one either sees them with the naked eye or sees mirror images or photographs or fossils or footprints of them - but not when one sees drawings of them ... It may not be desirable for our theory to recognize, in addition, a more restricted notion of perceiving or seeing, one which better fits the cases in which we use these everyday expressions; there simply may be no such natural kind. We should be prepared for the possibility that there is no very important distinction which even approximates the difference between perceiving things, in any everyday sense, and not perceiving them - that what we need is a radical reorganization of our concepts in this area' (Walton 1983: 275n).

${ }^{14}$ Although Walton never defines the notion of 'being in contact with', his discussion of the examples indicates that it is best understood as being unmediated by concepts, descriptions and so on. He writes, 'When someone describes a scene to
} 
Now clearly, 'being in contact with', so understood, is broad enough to cover cases in which one is related to things one remembers or thinks of by their names. In other words, if one has any thought about the thing with which one is in contact, the thought one has is de re in the sense I described earlier. If this interpretation is correct, Walton's transparency thesis would not appear particularly interesting to us, as all we can draw from it is that image-based thought is de re, something that has already been established. However, as I wish to show in the following, if we stick to a restricted sense of seeing or perceiving and give a literal reading of Walton's claim that the viewer of a photograph sees literally the scene photographed, an insight that seems very difficult to reconcile with his proposed radical reorganization of our concepts to suite the broad notion of 'being in contact with', apparently a non-literal understanding of 'seeing', some interesting discovery may be made, the discovery concerning what constitutes seeing something through an image as a form of perception, and as something different from other forms of non-conceptually mediated contact.

It should be recognized that what makes something an image of something else must include its having the properties that perceptually appear to us to be qualitatively similar or identical to the properties of the latter as they perceptually appear to us. Simply, the image must look (or sound) like the thing of which it is an image at a tolerable degree. ${ }^{15}$ The transparency of an image should therefore be understood in terms of not only the causal relation between the image and the thing it represents, which the broad notion of 'being in contact with' captures, but also its ability to allow us to have the perceptual experience

us, we are doubly removed from it; contact is broken both by the intervention of the person, the teller, and by the verbal form of the telling. Perceptual contact can itself be mediated by mirrors or television circuits or photographs. But this mediation is a means of maintaining contact' (Walton 1983: 273).

${ }^{15}$ A rather vague idea of 'look (or sound) like' will suffice to distinguish images that resemble the things they represent from those that do not. The mosaic image of Emperor Justinian in St. Vitale, Ravenna is an image of the emperor, despite the fact that it is not an accurate or adequate representation of him for being highly stylized and not sufficiently realistic. But an image that looks like nothing but an olive tree, for example, cannot justifiably be taken as an image of the Byzantine ruler (it may be used as a symbol of him), even if it had been so intended by the artist who created it, because the causal relation between the object the image represents and the image alone does not make it an image representation, but only a representation of some sort. 
that is qualitatively similar or identical to the perceptual experience we have of the thing itself, although the qualitative similarity or resemblance need not be at a degree that enables us to identify the object the image represents. A literal reading of Walton's claim that the viewer of a photograph sees literally the scene photographed may be formulated as follows: The particular perceptual experience the viewer has when she sees a photograph is (1) ultimately caused by the scene photographed (the perceptual experience is caused by the photograph which is in turn caused by the scene), and (2) qualitatively similar or identical to the perceptual experience directly caused by the scene itself. That is, being an image of some object is determined by the causal connection it has with the object, regardless whether it enables us to identify the object. ${ }^{16}$ But as an image it must bear some resemblance to the object at a certain degree, or, the image should be recognizable as an image of something at least as a certain type, for otherwise it is not an image, but something else, a symbol for instance. Now these characterizations encourage quite naturally classifying image-based thought as simply a sub-class of perception-based thought: image-based thought, if there is such a thing, is merely a variant of standard perception-based thought, and the only difference between these two is that the former is mediated by an image, whereas the latter is not by anything. Given that images are transparent, image-based thought is not different in essence from standard perception-based thought.

So far so good. But one thing that cannot be simply ignored is that when seeing an object by looking at an image of it, we normally or typically entertain a sense of illusoriness, which we normally or typically do not when looking at the object itself, ${ }^{17}$ a sense that can hardly

${ }^{16}$ The image of Louis XIV stands in a causal relation to the real person Louis XIV in much the same way the name 'Louis XIV' stands in a causal relation to him. It is an image of Louis XIV, the king who ruled France between 1661 and 1715, and of no one else. One can imagine, with the help of Alexandre Dumas, that the king had a twin brother who looked exactly like him, and therefore would fit perfectly the image in Rigaud's painting. As a result, the painting would in no way enable us to distinguish one from the other. But there is no doubt that the image is still of the king, not of the man who lived his later life in the iron mask, if there had existed such a person, as only the king was the cause of that image.

${ }^{17}$ Of course, whether the object being thought is actually present does not necessarily determine whether the thinker has the awareness of its presence. She can be totally deceived by the image and takes it to be the thing itself. In that case, she 
be said to contribute nothing whatsoever to the way we think of that object. This sense of illusoriness is clearly an indication of our awareness of the absence of the object the image represents. The viewer of the portrait of Louis XIV, for instance, knows that the man she is thinking of is somehow made present by the image in his absence, and this knowledge is an integral part of her thinking of the king. By contrast, if she perceives the king, not just an image of him, any thought she has about the king based on such perception will normally be accompanied by a different awareness, i.e., her awareness of his presence. This difference in awareness should determine in part the way we think of the object.

Contemplating on the same kind of slippery slope and the possibility of its being simply a work of the misleading ordinary concept of perception, Gareth Evans urges a closer examination of the commonality and difference between a standard case of perception (i.e., perceiving something directly) and a non-standard case of perception (i.e., perceiving it through its image). According to Evans, in both cases, there is a perceptual information link between the subject (one who perceives) and the object perceived (either directly or through its image) in the sense that the subject receives perceptual information about the object derived from the object. The perceptual information about the object may be understood as the content of one's perceptual experience of the object. While the sheer existence of the information link does not distinguish the standard case of perception from non-standard ones, Evans argues that in the standard case of perception one's perceptual experience of the object is accompanied by, if not consists of, his knowledge of the location of the object, whereas such knowledge is not present in the non-standard case. ${ }^{18}$ Evans' characterization of the difference, I think, points in the right direction for our understanding of image-based thought. On Evans' view, when one is said to perceive $\mathrm{X}$, it is understood that one knows at least where $\mathrm{X}$ is to be found in what Evans calls 'egocentric space' (a space where 'here' and 'there' are used), although one may not know what it is. If I see a man walking on the street, I know, for instance, that he is over there. My ability to locate the man can be manifested by a pointing gesture which in normal circumstances is sufficient to allow others know which man I am see-

entertains no sense of illusoriness at all. On the other hand, she will have a sense of illusoriness when she takes the real thing as a mere image.

${ }^{18}$ Evans 1982: 143-151. 
ing. By contrast, when I see a man in a picture, I cannot know where he is by simply looking at the picture. The man is not over there, and he may no longer be anywhere, as in the case of Louis XIV. Certainly I can still manage to let others know that it is the person whom I am seeing by pointing at the picture. But all I can locate is the picture, the immediate source of the perceptual information about the king I receive, and not the king himself.

While recognizing that one can perceive an object through its image, Evans flatly denies that one can think of it without the knowledge of its location. By this, he effectively denies image-based thought. Evans adopts what he calls Russell's Principle, which states that to think of a particular object, one has to know which object it is, and to know which object it is is to identify it, or to be able to discriminate the object from all other things. ${ }^{19}$ One can think of an object by a definite description, because the uniqueness of the description ensures a successful identification of it. In thinking of something non-descriptively (e.g., thinking of it based on perception, memory or communication) one must be able to identify it non-descriptively (or in Evans' terms, demonstratively), which must include as a necessary condition one's ability to locate the object. Since in cases involving perception of things through their images the information about the location of the object is not obtainable from the perception of it, one is not able to think of the object represented by its image, unless one is supplied with some descriptive information which can descriptively locate the object. For instance, if we wish to identify an unknown person seen on a photograph, we may need to know where and when the photograph was taken, etc. Only when we are equipped with this knowledge are we in the position to think of that person. ${ }^{20}$ Thus for Evans, the viewer of the portrait of Louis XIV cannot form any adequate thought about the French king, given her total lack of information about the king, including that of his location. As a consequence, although Evans recognizes an important theoretical difference between the standard case of perceiving and the non-standard one, he does not consider image-based thought to be sui generis in the sense I have described. Thinking by

$$
{ }^{19} \text { Evans 1982: } 65 .
$$

${ }^{20}$ However Evans maintains that such descriptive element does not make the identification of things in these cases descriptive. The identification is still demonstrative, because it does not rely solely on the descriptive element (see Evans 1982: 149). 
image is possible, Evans maintains, only if some descriptive information about the location of the object is supplied to compensate for the lack of the perceptual information about its location on the part of the image itself. Evans sees thinking by image so defined to be only a nonstandard case of thinking based on perception, and hence an extension of the latter. However, if the standard case of thinking based on image, as I shall argue, is understood as one in which one can think of the object in the absence of any information, whether descriptive or perceptual, about the location of the object, then the kind of thinking involving images as described by Evans should be rather treated as a non-standard case of thinking based on image, rather than a nonstandard case of thinking based on perception.

Evans' denial of the possibility of what I call the standard case of thinking based on image rests on two premises: (1) To think of an object perceived through its image, one must identify the object. (2) To identify the object so perceived, one must be supplied with some descriptive information about the location of the object to compensate the lack of perceptual information on the part of the image. Now I wish to show that both premises are problematic. I agree that some descriptive information about the location of the object is needed for identifying it demonstratively, but only in some cases involving images. In some other cases we can identify an object demonstratively without this information. For instance, we can identify someone by a picture of him or even his recorded voice, if the picture or the recorded voice contains information about some unique perceptual features of the person. Such identification is demonstrative and not descriptive, as it is solely based on the content of the image, that is, a set of the perceptual features of the image which bear resemblance to those of the real person, and which enable us to pick out the person the image represents. Such a set of perceptual features may be translatable into, but is itself not, a definite description ${ }^{21}$. It is crucial that for such an identification to succeed, the image provides information about the perceptual features unique to the object. Normally, sufficiently detailed information about the perceptual features of the object will do. We would not expect a heavily blurred snapshot image of someone accidentally caught on the camera to offer much

\footnotetext{
${ }^{21}$ The utility of surveillance cameras, still photographs and even drawings are a testimony to the effectiveness of such non-descriptive identification.
} 
chance for successfully identifying him. But what really counts is not how detailed the information is about the perceptual features of the object, but how adequate the information is about the unique perceptual features of the object. A rough sketch that contains much less detailed information about an object it represents than a more realistic painting of the same object can just be as good as, and perhaps even superior over, the latter in enabling us to identify the object. ${ }^{22}$

However, whether or not this second premise should be rejected seems to matter little if the first premise is unacceptable. The first premise is an instantiation of Evans' general claim central to his theory of thought that thinking of a particular object requires identifying it (or being able to discriminate the object from all other things), which is by no means universally endorsed and is in fact quite controversial. ${ }^{23}$ Evans advices that we should carefully distinguish saying of or referring to something from thinking of it, and that one's being able to say of or refer to something does not entail that one can actually think of it. ${ }^{24}$ That is, for instance, although I can refer to the French king by the name 'Louis XIV' simply because of the right causal bloodline in

${ }^{22}$ Certainly if the object itself cannot be perceptually distinguished from some other objects due to the lack of unique perceptual features, as in the case of Louis $\mathrm{XIV}$ and his twin brother, an image representing it, however faithfully, will not help us to identify it.

${ }^{23}$ Bach, for one, has argued against it. He writes, 'You can think of a perceptual object merely by attending to it. If you look away and then turn back, you needn't be able to perceptually to pick it out of a crowd, even in the midst of look-alikes. Similarly, you can think of an object you have perceived before merely by remembering it. That you remember something, hence your ability to think of it, does not require that how you remember it distinguishes it from other things. ... And if someone refers you to something by name, you can think of it simply by name. Of course, if you know of several individuals with that name, you may not know which one he is talking about, if any, but this does not prevent you from thinking of it' (Bach 1987: 44). While I agree with Bach's criticism of Evans' general thesis, I consider his conception of perception based thought without discriminating knowledge to be false. As I see it, when perceiving an object, one necessarily possesses discriminating knowledge, i.e., the knowledge of locating it. The ability to locate the object is a necessary part of one's ability to perceive it. By attending to an object I am locating it. If I look away and then turn back, but cannot perceptually pick it out of a crowd, I no longer perceive it. If I no longer perceive it, I may have a memory based thought about it, but not a perception based thought.

${ }^{24}$ Evans 1982: 76-79. Apparently Evans here assumes the Strawsonian conception of referring: referring is something people do, and not something words do. 
my use of the name, I cannot think of him if I do not have some discriminating knowledge. Now to say that I can refer to the person by that name is simply to say that I can refer someone else (an audience) to him. But what exactly does it mean to say that I can refer someone else to him? It cannot mean but making her think of that person. If that someone else lacks the discriminating knowledge, it would appear that I cannot refer her to that person. Moreover, if, as Kent Bach points out, rightly I think, thinking of something is necessary for referring to that thing, ${ }^{25}$ again I cannot refer someone else to Louis XIV, if I myself cannot think of the king in the first place. Thus, if my history teacher refers me to someone by the name 'Louis XIV', I can think of the person just by that name, without any discriminating knowledge that would enable me to identify him. Surely, I would possess some knowledge about the person transmitted from my teacher, for example, that he was a king, or even that he was a French king, information that is associated with the name when I acquire it. ${ }^{26}$ However, this knowledge is clearly not enough for me to distinguish him from other French kings, say, Louis XIII, Louis XV, and Louis XVI. Similarly, if my history teacher refers me to Louis XIV by saying, 'this man is known as Le Roi Soleil', when pointing at a picture of him, I can think of him just by that picture, even though I have no discriminating knowledge that enables me to distinguish him from all others. How can my teacher succeed in referring me to (that is, making me think of) that person while I fail to think of him? One option for Evans to avoid this is to deny that one can refer to something by name without being able to identify it, which, however, does not seem promising for someone who does not object in principle to the causal account of reference by name.

With regard to the particular instantiation of Evans' general thesis, some comparison between image based de re thought and the other kinds of de re thought should help make my case. I agree with Evans that thinking of an object by perception necessarily involves knowledge about the location of that object. But that knowledge need not

\footnotetext{
${ }^{25}$ This is a point derived from Strawson's conception of referring (see Strawson 1950: 320-44).

${ }^{26}$ Such information may be understood as pertaining to what Adèle Mercier calls commitments de dicto, that is, commitments to the sort of word a word being used is (see Mercier 1999).
} 
be retained when I think of the object again by memory, even in the absence of any other discriminating knowledge that allows me to identify it, should I encounter it again. That is, while I might totally forget where and when (except perhaps on this earth and in the past) I saw the object, I do remember that I saw it. And I do not just remember that I saw the object, I also remember that I was able to locate it. There is no reason to deny that in remembering all these, I am thinking of the object, the same object I saw. Similarly, if I took a picture of an object I saw, and later look at the picture, I can think of the object represented by the picture, because I remember that I took this picture and I saw the object captured by the picture, even though I may forget where and when I saw the object and took the picture.

Now suppose the picture was taken by someone else, who then shows it to me, such that my memory plays no role. Can I think of the object by looking at the picture? I think I can. The reasons for this are derived from those that support the idea of communication based de re thought, which have been explained by Bach in a rather clear manner. Bach suggests that in order for a speaker to enable a hearer to think of an object the speaker thinks of in a de re way, the speaker can not only express (i.e., by description) but also actually display her de re way of thinking of the object. By this, he means the following: When the speaker, who entertains a mental token of the name of that object she is thinking of, refers the hearer to the object, she produces a physical token of that name. Upon hearing that token, the audience forms a mental token of the same name, which she can retain in her memory. The hearer's mental token of the name 'inherits' the same object as the speaker's by having a certain form (sound or shape), generally the same as the speaker's. ${ }^{27}$ 'Since the token of a name represents in virtue of its form, not its meaning, its representational features can be perceived by the hearer, who can then and thereafter use mental tokens of the same name to think of (or refer to) the same object' (Bach 1987: 32-33). A picture of an object taken by someone else plays a role quite similar to that of a physical token of the name of

\footnotetext{
${ }^{27}$ While I accept Bach's general view on the role the form of a name plays in determining the object a token of that name 'inherits', I recognize the complications with regard to what counts as the form of a name, that is, for instance, whether similarity of sound and shape is sufficient for formal identity, and even whether formal identity itself is sufficient for a token of a name to 'inherit' a particular object. For discussions on these questions, see Mercier 1999.
} 
the object produced by the speaker, in that the picture represents the object in virtue of its form (perceptual features), which can be perceived by me. The picture taker, when referring me to the object by showing me the picture, is also displaying her de re way of thinking of the object, though in a different way: She does not need to entertain a mental image of the object in order to refer me to the object. Nor do I need to form a mental image of the object so that I can think of it. I can have de re thoughts about the object by perceiving the picture, because in showing the picture to me, the picture taker is displaying her perception based de re way of thinking of the object. 'This is what I saw', she may say to me. However, whether or not there is someone who actually refers me to the object by showing me the picture is not really important. I can certainly conceive there being someone who perceived the object and had some de re thoughts about it, although I have had no contact with her. And I can even entertain the possibility of there being no such person at all, should the picture be mechanically produced with no human intervention. Either way, I can still think of the object in a de re way, because the picture itself displays the perception based de re way of thinking of the object which whoever perceived the object would display. After all, what the picture taker does is nothing more than showing me the picture, which need not be accompanied by the remark 'this is what I saw'.

Finally I wish to appeal to some slippery slope considerations which hopefully can offer further justification at a more intuitive level for the idea of thinking by image. The slippery slope considerations, though similar to Walton's, are meant to show not the absence of differences between perceiving an object and perceiving its image as in Walton, or between thinking of an object by perceiving it and thinking of it by perceiving its image, but only the absence of differences with regard to the ability to think of an object we have between when perceiving an object and when perceiving its image, or the irrelevance of the knowledge of the location of the object in our thinking of it. Upon seeing Tutankhamen's mummy, a visitor may say to herself, 'this guy might look quite handsome.' Does the visitor think of the ancient pharaoh of Egypt who died thousands years ago? It seems difficult to deny that she does, given that her thinking in this case is not far different from her thinking of the old man she is seeing walking nearby - she can think of the man at his early age while visually following his sluggish pace, as in a sense, the mummy is the same thing as the young pharaoh, separated from the latter only by time. If she can think of a boy who has now 
become the old man nearby, she can think of the pharaoh as well. In another sense, the mummy is not the pharaoh, the real person, for, as Aristotle has said, a dead man is not a man. (But we can also say that a boy is not an old man in some sense). Inasmuch as the mummy is not the pharaoh, why must the relation between them be considered fundamentally different from that between the golden mask on the coffin depicting the pharaoh and the pharaoh himself? After all, the pharaoh can be said to have survived in the mummy only in a metaphorical sense (not in the sense the ancient Egyptians believed he had), the sense in which he can also be said to have survived (or immortalized as we may also say) in his image. To identify the pharaoh, the visitor who perceives the mummy would need some discriminating knowledge, which she should not expect to obtain from looking at the mummy, if it does not come from elsewhere. Now if the visitor can think of the pharaoh by looking at the mummy, she can also think of him by looking at the mask.

To sum up, the difference between perception-based thought and image-based thought is that the former necessarily incorporates the knowledge of the location of the thing and the latter does not. One's merely perceiving the image of something is the sufficient and necessary condition for one's having an image-based thought about that thing. But there remain some questions with regard to such a characterization of the difference. For instance, is a thought based on seeing a distant star that is long gone a perception-based thought or an image-based thought? Since such seeing by itself does not provide demonstrative information about the location of the star, the thought based on it seems to fit our description of image-based thought. But clearly there is no image which mediates the viewer and the star. Perhaps it should belong to neither category. For the moment, I shall content myself with the solution that it is of yet another kind of thought which requires a separate treatment. ${ }^{28}$

$$
\begin{array}{r}
\text { Xiaoqiang Han } \\
\text { Department of Philosophy } \\
\text { Queen's University at Kingston } \\
\text { Kingston, Ontario K7L 3N6, Canada } \\
\text { hanxiaoqiang@gmail.com }
\end{array}
$$

\footnotetext{
${ }^{28}$ I thank Professor Adèle Mercier for encouraging me to develop the ideas in this paper and the two anonymous referees for their insightful comments and suggestions for improvement which helped bring it to its current form.
} 


\section{References}

Bach, K. 1987. Thought and Reference, Oxford: Clarendon Press.

Beebe, M. 1979. How Beliefs Find Their Objects. Canadian Journal of Philosophy 9: 595-608.

Burge, T 1977. Belief de re. Journal of Philosophy 74: 338-62.

Evans, G. 1982. The Varieties of Reference, ed. J. McDowell, Oxford: Clarendon Press.

Kaplan, D. 1989. Afterthought. In Themes from Kaplan, ed. by J. Almog, J. Perry and H. Wettstein. New York: Oxford University Press.

Mercier, A. 1999. On Communication-Based De Re Thought, Commitments De Dicto, and Word Individuation. In Philosophy and Linguistics, ed. by R. Stainton. Boulder, CO: Westview Press.

Quine, W.V. 1956. Quantifiers and Propositional Attitudes. The Journal of Philosophy 53: 177-187.

Strawson, P.F. 1950. On Referring. Mind 59: 320-44.

-. 1959. Individuals: An Essay in Descriptive Metaphysics. London: Methuen.

Walton, K. 1983. Transparent Pictures: On the Nature of Photographic Realism. Critical Inquiry 11: 246-277. 